\title{
¿QUÉ IGUALDAD?
}

ANTONIO TORRES DEL MORAL

Catedrático de Derecho Constitucional

UNED 


\section{SUMARIO}

1. Introducción. 2. Múltiples apelaciones a lo social y a la igualdad en la CONSTITUCIÓN ESPAÑOLA. 3. LA IgUALDAD COMO VALOR. 4. LA IGUALDAD COMO DERECHO. 5. LA IGUALDAD COMO PRINCIPIO JURÍDICO Y COMO PRINCIPIO POLÍTICO. 6. LA IGUALDAD REAL Y EFECTIVA COMO INGREDIENTE DE LA IGUALDAD ANTE LA LEY. 


\title{
¿QUÉ IGUALDAD?
}

POR

\author{
ANTONIO TORRES DEL MORAL \\ Catedrático de Derecho Constitucional
}

UNED

\section{INTRODUCCIÓN}

El debate ideológico fue muy intenso durante la transición política española. El largo proceso constituyente, que duró casi año y medio vio cómo se "centraban" algunas opciones políticas, pero mantuvo en pie las suficientes vías de interpretación del texto fundamental como para que los comentaristas se alinearan en varias posiciones en la "lectura" y eventual desarrollo ulterior del mismo. Efectos del consenso. Hubo algunas contribuciones teóricas al estudio de las ideologías -o fragmentos de ellas - detectables en la Constitución: liberal, democristiana, socialdemócrata... Los estudios sobre la inicial declaración constitucional "España se constituye en un Estado social y democrático de Derecho", sobre la denominada "constitución económica" (propiedad privada, economía de mercado, planificación, intervención pública...) etc., pusieron de relieve esas posibles inclinaciones, siempre dentro de la ortodoxia constitucional, según fueran sucediéndose las mayorias gobernantes.

Vamos a tratar aquí de la igualdad, que es en cierto modo - lo mismo podríamos decir de la libertad - el problema de la humanidad. Bien lo vio Russeau en El origen de la desigualdad entre los hombres; y el mismo Aristóteles, en su Política, sentenció con claridad y concisión que todas las revoluciones tienen como origen la desigualdad. 
Como no podía ser menos, también este nuclear asunto recibió diversos enfoques en la transición y primeros años de vigencia de la Constitución. Los autores se decantaron entre la defensa de la tradicional igualdad ante la ley como la más expresiva del Estado de Derecho proclamado y única compatible con el valor libertad, y la apuesta por la más innovadora igualdad real y efectiva como la más propia del Estado social también proclamado y única que no desdice del valor justicia. Se reeditaba así una de las polémicas más inútiles y en las que se ha hecho mayor acopio de argumentos vacios de toda la historia del pensamiento político: la que opone sistemáticamente la igualdad y la libertad como principios, valores o fines políticos contradictorios entre sí.

Se dice con más voluntad que acierto que la igualdad perjudica a la libertad; y se pone como ejemplo la antigua Unión Soviética, con su cortejo de las denominadas democracias populares, $y$, todavía en nuestros días, se mira indisimuladamente a Cuba. Del lado contrario, se replica con énfasis que la libertad se construye a costa de la igualdad; y se mienta a EE.UU. como país paradigmático del sistema capitalista. Si en las ciencias sociales todos los asuntos se pudieran despachar con tan alegre superficialidad, sobrarían el $99 \%$ de las bibliotecas especializadas.

Hemos de añadir que, de esos dos fines políticos esenciales, que junto a la fraternidad o solidaridad componían la divisa revolucionaria, la igualdad ha sido permanentemente colocada en un segundo lugar en aras del predominio de una sedicente libertad de la que muy pocos llegaban a disfrutar, que muy pocos llegaban a ejercer. Así ha ocurrido al menos en los regímenes demoliberales, en los Estados de Derecho eurooccidentales, los únicos que han existido, por lo demás, aunque sólo sea tendencialmente. Lo curioso es que haya sucedido, según se ha dicho, precisamente para mejor preservar el Estado de Derecho, puesto que una extensión de la igualdad era temida como un riesgo para la libertad.

Es ésta una teoría que, aunque claramente decimonónica y conectada a los valores liberales predemocráticos, sigue teniendo muchos defensores en la actualidad, y hasta en número creciente desde la caída del Muro de Berlín y, con él, de los regímenes comunistas europeos. Se trata de una teoría que funde la legitimidad con la legalidad sin preocuparse demasiado de lo que esa legalidad encierra y encubre. Los derechos y libertades que defiende son los civiles y políticos, no los económicos ni los sociales. No requieren del Estado prestaciones sociales, sino sólo vigilancia y represión de las posibles perturbaciones 
de la legalidad. Dicho sea todo esto sin perjuicio del reconocimiento del inmenso avance que el Estado liberal significó respecto del Antiguo Régimen.

$Y$, sin embargo, toda una corriente de pensamiento ha habido en Europa que entendió con justeza que la idea de democracia no podía desligarse de la de igualdad. Durante el proceso histórico de incubación del Estado constitucional, del Nuevo Régimen, la democracia fue entendida como autogobierno popular directo en una sociedad caracterizada por la igualdad.

En efecto, como es de fácil memoria, MONTESTQUIEU cifró en la igualdad el principio motor de la república democrática, en tanto que ROUSSEAU cimentaba su modelo de sociedad deseable en un contrato social igualitario. $Y$ todavía a mediados del siglo XIX, un autor tan poco sospechoso de veleidades democráticas como TOCQUEVILLE vio en la igualdad la esencia de la democracia1.

Que después hayamos terminado hablando de democracia en sociedades claramente desiguales es algo que forma parte de la procelosa historia del concepto de democracia. Pero recordemos que todavía a fines del XIX los conservadores españoles, y también la Iglesia Católica oficialmente, se oponía a la democracia con el argumento de que llevaría necesariamente al socialismo. Poco a poco, el concepto de democracia ha cambiado tanto que hoy en dia ninguna ideología politica puede monopolizarlo, al menos tal y como actualmente se la entiende.

Creo que todo lo dicho merece una reflexión.

La burguesía liberal disociaba la realidad en dos regiones separadas y frecuentemente antagónicas: el Estado y la sociedad civil. La sociedad civil era la esfera del libre juego "natural" de las fuerzas individuales, supuestamente iguales, que el Estado no debía alterar, sino dejar en libertad. Y ello tanto en el ámbito económico cuanto en el político.

La realidad era bastante distinta: ni las personas operan sólo como individuos, sino insertas en el seno de grupos, ni son tan iguales, ni, por tanto, tan libres, sino que sus diferentes situaciones sociales las

1 Aunque también su espanto, porque, decía, el deseo de igualdad lleva a los ciudadanos a requerir la intervención de los poderes públicos y esa progresiva intervención y crecimiento de la Administración sofocaría irremisiblemente la libertad. 
fuerzan y las condicionan en un sentido o en otro. Por eso el cuarto estado, el proletario, reclamaba democracia, sufragio universal, para poder participar en el poder político $y$, desde él, actuar sobre la sociedad en busca de una mayor igualdad. TOCOUEVILLE, una vez más, lo supo detectar con suma pulcritud: el problema del Nuevo Régimen, tanto en Europa como en América, era la organización de la igualdad en el seno de una sociedad libre. Es decir: la construcción de una sociedad al mismo tiempo libre e igualitaria, una sociedad en la que cupieran y se coimplicaran la libertad y la igualdad sin detrimento de ninguna de las dos.

La filosofía jurídica ha depurado mucho los conceptos de libertad e igualdad y hoy se distingue - dejando a un lado otras muchas especies - entre libertad negativa y positiva, entre libertad de (freedom from, ausencia de restricción o de coerción de la voluntad) y libertad frente a (freedom to, libertad resistencia), así como entre igualdad jurídica y sustancial o material, y entre igualdad jurídica y política. Puede apreciarse alguna oposición dialéctica entre unos tipos de libertad y de igualdad, pero no entre todos, y menos aún entre la libertad y la igualdad como conceptos enteros y globales².

Este desarrollo más matizado de los conceptos que estamos relacionando procede no sólo del socialismo, sino del liberalismo que pudo ser y no fue, un liberalismo de primer cuño mucho más sensibilizado socialmente que el triunfante decimonónico y que quedó olvidado durante casi siglo y medio. Su representante mas temprano y genuino fue CONDORCET, por eso mismo considerado - hiperbólicamente, sin duda - en algunas historias del pensamiento político como protosocialista.

Este "filósofo", que también lo era sin comillas, coetáneo de la Revolución francesa y que tanto contribuyó a su desarrollo, expuso un concepto de igualdad que, sin ser el de Babeuf, puesto que parte de posturas fisiocráticas y sustenta tesis netamente liberales, acierta a romper - ya desde el inicio - la oposición entre libertad e igualdad y a ofrecer, por tanto, una imagen diferente de lo que pudo haber sido el liberalismo posterior. Para Condorcet, como para todo buen ilustrado, la desigualdad puede ser natural o institucional; esta segunda es "obra arbitraria de las instituciones sociales", consecuencia de "las imperfecciones del arte social", por lo que, a diferencia de la primera, sí hie-

2 Cfr. por todos, Bоввіо, N.: El tiempo de los derechos, ed. cast. Madrid, 1991, passim; y Libertad e igualdad, ed cast. Madrid, 1993, passim. 
re el derecho a la igualdad. La igualdad es un ingrediente necesario de la libertad, de manera que sin aquélla no existe ésta, como tampoco la paz ni la felicidad 3 .

Hasta aquí había llegado también ROUSSEAU. Pero el filósofo geómetra dio un paso más: "No perdamos de vista que igualdad de derechos y libertad son sinónimos"4.

El principio liberal de dejar hacer entró en crisis con la Primera Guerra Mundial por su incapacidad de asegurar el orden económico en unas sociedades como las europeas de aquellos momentos. El liberalismo, en su versión keynesiana, y el socialismo, en su versión socialdemócrata, convergieron en el Estado social y después de la Segunda Guerra Mundial muchas constituciones adoptaron el adjetivo social para definir el régimen político que instauraban; hasta la monarquia diseñada por Franco Bahamonde en la Ley de Sucesión de 1947 se apellidó social.

El Estado social -o el Estado social de Derecho, en expresión afortunada de $\mathrm{H}$. Heller - asume la tarea de la igualdad como una función política, para lo cual necesita utilizar un poder que hasta entonces le había sido ajeno: el poder económico, con el que organiza, concierta, dirige y planifica la economía de una sociedad. En el Estado social y democrático de Derecho la libertad tiene una clara vertiente positiva, superadora de la concepción liberal vigente hasta el período de entreguerras, que la cifraba exclusivamente en la autonomía individual. Esta libertad social y positiva exige prestaciones estatales que posibilitan el efectivo desarrollo de la persona, se empareja con la igualdad $y$ demanda del Estado una función redistributiva y compensadora de las diferencias sociales.

Todo ello viene sintetizado en la Constitución española en el artículo 9.2, el más expresivo, al decir de buena parte de la doctrina, del Estado social y democrático de Derecho del que habla el artículo 1.1. Aquel precepto, efectivamente, no se conforma con la igualdad ni con la libertad meramente formales o declarativas, sino que pone como norte de la actuación de los poderes públicos la libertad y la igualdad reales y efectivas. El Tribunal Constitucional ha interpretado dicho precepto como proyección del carácter social del Estado, vinculando la

3 CONDORCET: Lettres d'un bourgeois gentilhomme aux mesieurs du tiers état, O. C., XII, 313-314. Cito por la edición de Henrich, Fuch, Köening y Lerrault, Schöel y Cía., 1804 (año XIII).

4 Id.: Essay sur les Assemblées Provinciaux, O. C., XIV, 415. 
efectividad de la igualdad y de la libertad al objetivo de garantizar un bienestar material generalizado.

\section{MÚLTIPLES APELACIONES A LO SOCIAL Y A LA IGUALDAD EN LA CONSTITUCIÓN ESPAÑOLA}

La Constitución española se instala ciertamente en la posición que hemos venido describiendo. El artículo 1.1 define el Estado como social y democrático de Derecho. El mismo artículo 9.2 habla de la participación en la vida social, económica y cultural al mismo tiempo que de participación política. El capítulo III del título I está íntegramente dedicado a fijar los principios de la política social y económica, que después se ven instrumental o institucionalmente desenvueltos en el título VII, que lleva como rótulo "De Economía y Hacienda".

$Y$ en esos principios de política social y económica se habla de protección social y económica de la familia, de promoción del progreso social y económico, de extensión de la Seguridad Social a todos los ciudadanos, de participación de la juventud en el desarrollo político, social, económico y cultural...

Hay, pues, una clara preocupación por construir un Estado social. $Y$ aunque algunos han querido ver en la denominación de "Estado social y democrático de Derecho" una contradicción en los términos, entiendo que no sólo no hay contradicción entre lo social, lo democrático y lo jurídico, sino que únicamente las exigencias formales -jurídicas de la democracia pueden impedir que el Estado social derive hacia un Estado totalitario.

Si la idea de lo social está presente por doquier en la Constitución española, no otra cosa sucede con la de igualdad. No es extraño por eso que el Tribunal Constitucional haya tenido en la interpretación del principio de igualdad, y fundamentalmente a través del artículo 14, una buena parte de su trabajo.

1) El artículo 1.1 propugna la igualdad como valor superior del Ordenamiento jurídico. Hay en ello un cierto solapamiento con el valor superior de la justicia, si es que entendemos por igualdad no un estricto igualitarismo, sino, al modo aristotélico, una igualdad proporcional que trata igual a los iguales y desigual a los desiguales; no otra cosa es la justicia, que da a cada uno lo suyo, lo suyo que ya tiene o que deberia tener. No está lejos de este tratamiento la mismísima concepción 
marxista (si se me perdona el pecado de una cita tan insólita en los tiempos que corren) que reclama de cada cual según su capacidad $y$ asigna a cada cual según sus necesidades.

2) En segundo lugar, la Constitución española dedica especial atención a la tarea de la compensación de las desigualdades, bien naturales, bien institucionales o socialmente establecidas. Ejemplo de lo primero es la declaración del artículo 49 sobre los minusválidos o del articulo 50 sobre la tercera edad. En cuanto a las desigualdades socialmente establecidas y su deseable superación, el precepto más importante es el ya mencionado artículo 9.2, que habilita a los poderes públicos para hacer una remoción de obstáculos y una promoción de condiciones a fin de conseguir una igualdad real y efectiva. Por su parte, el artículo 149.1.1. ${ }^{\text {a }}$ reserva a los poderes centrales la competencia exclusiva para regular las condiciones básicas que garanticen la igualdad de todos los españoles en el ejercicio de los derechos y en el cumplimiento de los deberes constitucionales.

3) En este mismo orden de consideraciones, aún es más explícita la posición constitucional respecto de la igualdad de sectores de la población que han estado siempre social y jurídicamente discriminados. Por eso ordena la Constitución la no discriminación de las madres por razón de su estado civil, ni de los hijos, sea cual fuere su filiación (intra o extramatrimonial); así lo hace el artículo 39.2, en tanto que el artículo 32.1 ordena asimismo la igualdad de los cónyuges en el matrimonio. (Estos mandatos constitucionales alteraron el Derecho de familia hasta entonces vigente, derogándolo, aunque la jurisprudencia del Tribunal Supremo se mostró muy reacia a aplicarlos antes de la reforma del Código Civil de 1981.) Y aún debemos incluir en este apartado la muy explícita prohibición que hace el artículo 35.1 de discriminación por razón de sexo en el mundo laboral, otro de los reductos tradicionales de la desigualdad.

4) Acaso pudiera decirse que no hacía falta tanto detalle en el texto constitucional, una vez que el artículo 14 establece en términos genéricos la igualdad jurídica, la igualdad ante la ley, entendido el término ley en un sentido lato, como sinónimo de norma, de Derecho objetivo. Sin embargo, veremos que no es ocioso que esta declaración venga acompañada de la prohibición de discriminación. La Constitución detalla, para prohibirlas, las discriminaciones históricamente más frecuentes, pero finalmente amplía su perspectiva para prohibir también la discriminación por razón de cualquier otra circunstancia personal o social. Esta formulación ha sido el eje del ensanchamiento del concepto de igualdad jurídica. 
5) En quinto término, el principio de igualdad se predica también del sufragio en los artículos 68,69 y 140 . Hay que decir, sin embargo, que los demás criterios electorales establecidos en la Constitución impiden que esa igualdad sea real y efectiva, principalmente en la elecciones al Senado, pero también -y esto es más preocupante- en las elecciones al Congreso. Añadamos que la Ley Electoral de 1985 no aprovechó los pocos resquicios que el texto fundamental le dejaba para mejorar la igualdad de sufragio, sino que dejó las cosas tal como venian haciéndose desde la transición política.

En fin, en este aspecto de la igualdad en la participación política, la Constitución la predica también respecto del derecho de acceso a las funciones y cargos públicos; así lo hace el artículo 23.2. Algo diremos más adelante de esta especie del género igualdad.

6) La igualdad es asimismo un principio esencial del sistema tributario, conforme al artículo 31.1.

7) Podemos decir, de otro lado y para concluir este elenco, que, así como existen en el título I de la Constitución unos derechos que vienen exigidos por el valor libertad (libertad de reunión, de asociación, de expresión, etc.), también existen derechos exigidos por el principiovalor igualdad, como son, en general, muchos de los de contenido social-económico, sea cual fuere su ubicación en el texto, aparte de los principios rectores de la política social y económica del capítulo III de dicho título.

Por consiguiente, la igualdad, como principio fundamental del Ordenamiento jurídico lo como valor superior del Ordenamiento jurídico, si preferimos el enfoque del artículo 1.1 de nuestra norma suprema), ha de presidir la interpretación de toda la Constitución y del resto de dicho Ordenamiento, muy especialmente de cuantos preceptos se refieren a los derechos y libertades. No en vano el artículo 14 está presidiendo el capítulo II del título I, con lo que se impone en la interpretación de todo él y no sólo de los pasajes que mencionan expresamente la igualdad.

\section{LA IGUALDAD COMO VALOR}

Desde el primer borrador de la Constitución, la doctrina acogió favorablemente la declaración del Estado como social y democrático de Derecho, asi como los valores superiores del Ordenamiento jurídico 
propugnados por dicho Estado. Pero también muy tempranamente aparecieron algunos matices respecto de éstos. Principalmente dos: 1) su número podía reducirse, puesto que la igualdad y la justicia se solapaban ${ }^{5}$ y otro tanto sucedía con la libertad y el pluralismo político6; 2 ) pero también podía y debía ser ampliado incorporándole la dignidad de la persona, ubicada en el artículo 10.1, etcétera7. Por contra, recientemente A. Garrorena ha defendido la dicción del artículo 1.1 tal como está8.

También desde un primer momento ${ }^{9}$ expuse mi análisis de la referida declaración constitucional en el sentido de que la igualdad no era propiamente un valor, sino un ente de razón, lógico o matemático, que pone en relación dos cantidades, cualidades, entidades, bienes o derechos. El valor reside en éstos, no en la igualdad o desigualdad que los relaciona. Cuando solicitamos la igualdad en el acceso a la enseñanza o la igualdad procesal de las partes, lo que en realidad estamos demandando es el acceso a la enseñanza y a los medios de defensa que nos están siendo negados en tanto se les reconoce a otros. Nadie reclama igualdad en la pobreza ni en la esclavitud; el concepto de igualdad es en estos supuestos el mismo que en los anteriores, pero no los términos de la comparación en la que toda igualdad consiste: en los casos enunciados en primer lugar son valiosos y en el segundo son desvalores.

Posteriormente he visto defendido este planteamiento - aunque con toda seguridad no por mi influencia- por F. Rubio Llorente y G. Peces Barba. "La igualdad es siempre, por eso, relativa, pues sólo en relación con un determinado tertium comparationis puede ser afirmada o negada", dice el primero ${ }^{10}$, que añade poco después: "El rasgo

5 Peces BArba, G.: Los valores superiores, Madrid, 1984, pp. 118 ss.

6 Torres del Moral, A.: Principios de Derecho Constitucional Español, 1. a ed.,

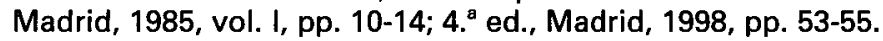

7 Así, unos autores reducen los valores del artículo 1.1 a la libertad y la igualdad (Peces BARBA, G.: ob. y lug. cit.); otros, a la libertad y el pluralismo político (PRIETo, L.: "Los valores superiores del Ordenamiento jurídico y el Tribunal Constitucional", Poder Judicial, n. ${ }^{\circ} 11$, Madrid, 1984, pp. 83 ss.), o incluso sólo a la libertad (TorRes del Moral, A.: ob. y lug. cit.), si bien en un momento lógico y antropológico ulterior se incorpora la justicia-igualdad.

8 Garrorena Morales, A.: "Valores superiores y principios constitucionales", en VV. AA.: Estudios de Derecho Público, Homenaje a Juan José Ruiz-Rico, Madrid, 1997, vol. I, pp. 30-33.

9 TorRes del Moral, A.: ob. cit., $1 .^{\text {a }}$ ed., Madrid, 1985, vol. l, lug. cit.; recogido igualmente en la $4 .^{a}$ ed., ob. y lug. cit.

10 Rubio Llorente, F.: “La igualdad en la jurisprudencia del Tribunal Constitucional", Revista Española de Derecho Constitucional, n. ${ }^{\circ} 31$, Madrid, 1991, p. 12. 
que se haya de tomar en consideración para hacer el juicio de igualdad habrá de ser siempre aquél que resulte siempre relevante para la finalidad de la distinción..."11. Y el segundo: "...la dificultad para la igualdad está en su indeterminación, es decir, que no significa nada sin identificar los titulares y las cosas respecto a las que son iguales. La libertad es una cualificación de la persona, mientras que la igualdad es un tipo de relación"12.

Parece, pues, que se han frenado algo los bríos "igualitarios" de los primeros comentarios. Lo cual, sin embargo, no puede llevarnos a excluir la igualdad del elenco de valores constitucionales. No sólo porque el texto fundamental la incluye y eso nos fuerza a una interpretación integradora, nada difícil, por lo demás; sino porque en un segundo momento del análisis lógico y antropológico resulta manifiesta su dimensión axiológica.

Porque, efectivamente, se llega al concepto de igualdad, al menos en su dimensión más elemental, con naturalidad y sin esfuerzo alguno, siendo, a partir de ahí, de utilización preferida y general dada la espontaneidad con la que hacemos continuamente juicios de igualdad, comparaciones. El valor primario y fontanal es la libertad, la libertad en su significado más radical como dimensión óntica del hombre, por delante incluso de la dignidad. El hombre no es libre por ser digno, sino digno por ser libre; como libre, es un fin en sí mismo y no tolera ser tratado como un mero instrumento; $y$, como libre y digno, rechaza ser tratado de modo desigual, discriminatorio, respecto de otro hombre. He ahí, a mi juicio, el orden lógico en un análisis antropológico de los valores.

Podemos decir, pues, que la vida social y política está sometida a un permanente juicio de igualdad, que todo lo valoramos en términos de igualdad y que, por eso mismo, no es un desatino ver en ésta un valor de esas vertientes de la vida humana. Teóricamente, no podemos perder de vista la sustancia relacional de la igualdad, que evidencia que lo valioso reside no en la relación o comparación, sino en lo relacionado o comparado, en el tertium comparationis; sin embargo, el hecho constatable de que la reivindicación de igualdad sea tan espontáneo pone de manifiesto la plausibilidad del paso lógico que se da entre la reclamación de bienes concretos y la reclamación de igualdad y la consecuente consideración de la igualdad como valor antropológico básico.

11 Ibidem, p. 18.

12 Peces BArba, G.:"Introducción" a BobBio, N.: Igualdad y libertad, ob. y ed. cit., pp. $45-46$. 


\section{LA IGUALDAD COMO DERECHO}

Como he tratado en otro lugar ${ }^{13}$, es dificilmente inteligible una reclamación judicial de igualdad en general. En línea con lo que hemos dicho más arriba acerca de la igualdad como valor, dicha demanda habrá de cifrarse siempre en bienes y derechos concretos, que son los que en realidad se postulan. Podríamos por eso calificar la igualdad más como un principio que informa el régimen de derechos y libertades que como un derecho (es lo que hace I. DE OTTO) ${ }^{14}$; o, en caso de querer seguir llamándolo de este modo, sería un derecho conexo, no autónomo.

La Constitución española así lo da a entender cuando ubica la igualdad en la cabecera del capítulo II del título I, como presidiendo las dos secciones del mismo que reconocen y garantizan los derechos concretos, pero sin incluirla en ninguna de ellas. Ni siquiera utiliza el artículo 14 la expresión "derecho a la igualdad" ni ninguna asimilable. Sin embargo, de modo explícito o implícito, todos los preceptos subsiguientes aluden a la igualdad como elemento del derecho que consagran. Asi hay que interpretar las locuciones "todos tienen derecho", "nadie podrá ser obligado", y también esas otras fórmulas impersonales de "se garantiza", "se reconoce", atribuidas a un derecho. Las excepciones y limitaciones, bien escasas, están expresamente determinadas en la Constitución. El resto hay que considerarlo informado de dicho principio.

Ésta es la interpretación que el Tribunal Europeo de Derechos Humanos hace del también artículo 14 que el Convenio dedica al principio de igualdad. Este precepto, dice el Tribunal, no tiene existencia independiente, sino que es complemento de las demás disposiciones normativas del Convenio y de los Protocolos, protegiendo a los individuos y a los grupos contra toda discriminación en el disfrute de los derechos y libertades que aquéllos consagran. Por tanto, cualquier acto que, pese a ser aparentemente conforme con un precepto del Convenio o de los Protocolos, tuviere carácter discriminatorio significaría una violación de ambos preceptos conjuntamente (del artículo 14 y del que regule el derecho en cuestión). De esta manera, el artículo 14 del Convenio "forma parte integrante de todos y cada uno de los diversos ar-

13 Torres del Moral, A.: Principios..., ob. cit., 4. ${ }^{\text {a }}$ ed., Madrid, 1998, pp.

14 Otto, I. de: "Igualdad", en González Encinar, J. J. (dir.): Diccionario del sistema político español, Madrid, 1985, pp. 450-451. 
tículos que garantizan los derechos y libertades, cualquiera que sea la naturaleza de estos últimos", dice el Tribunal15.

Respecto del Ordenamiento jurídico español, el Tribunal Constitucional ha dado entrada a una interpretación semejante. La igualdad reconocida en el artículo 14 de la Constitución "no constituye un derecho subjetivo autónomo, existente por si mismo, pues su contenido viene establecido siempre respecto de relaciones jurídicas concretas"16. Es derecho subjetivo, sí, pero no autónomo. Por eso puede ser objeto de amparo cuando es vulnerada en una concreta relación jurídica.

Que el artículo 14 de la Constitución española no consagre un derecho subjetivo autónomo no significa que carezca de contenido propio. Este contenido es la prohibición de toda discriminación, sobre la que habremos de insistir en un epígrafe posterior. Por eso no toda violación de un derecho fundamental es al mismo tiempo violación del artículo 14, pero si lo es toda aquella que comporte una discriminación.

Entiéndase, no obstante, todo lo que antecede referido exclusivamente a los españoles, lo cual plantea el problema del estatuto jurídico del extranjero, en el que, sin embargo no vamos a detenernos. Aduzcamos tan sólo que la tendencia internacional es la de ir ampliando los derechos y garantías de los extranjeros reconociéndoles los derechos civiles $y$, en ocasiones, bajo ciertas condiciones, también algunos derechos políticos. A esta tendencia responde la Constitución española, que, si en su artículo 14 no habla de ellos, en el que lo precede consigna que "Ios extranjeros gozarán en España de las libertades públicas que garantiza el presente título (el título I) en los términos que establezcan los tratados y la ley". El Tribunal Constitucional afirma que esa expresión de libertades públicas no tiene aquí un significado técnico restrictivo, sino amplio, equivalente a derechos y libertades. Asumido asi, la igualdad o desigualdad en la titularidad de derechos y libertades dependerá de lo que en cada caso dispongan la Constitución, los tratados y las leyes.

15 STEDH de 13-III-1978, caso Markx; una anticipación casi literal se encuentra en STEDH de 27-X-1975, caso Sindicato Nacional de la Policía Belga; cfr. igualmente SSTEDH de 22-C-1981, caso Dudgeon, y 29-XI-1983, caso Van der Mussele. 


\section{LA IGUALDAD COMO PRINCIPIO JURÍDICO Y COMO PRINCIPIO POLÍTICO}

La tinta corrió más, mucho más, enfrentando la igualdad ante la ley y la igualdad material, real y efectiva. Muchos autores identifican un tanto simplistamente ambos conceptos con las ideologías liberal y socialista (o, todavía más imprecisamente, con las ideologías conservadora y progresista); con lo que volvemos al debate con que iniciamos estas reflexiones.

De nuevo acudimos al pensador referido en páginas precedentes, que lo dijo antes y mejor que otros posteriormente mas atendidos por la Historia del Pensamiento Político: “...muchas veces existe una gran diferencia entre los derechos que la ley reconoce a los ciudadanos y los derechos de los que éstos realmente gozan; entre la igualdad establecida por las instituciones políticas y la que existe entre los individuos (...) esta diferencia ha sido una de las principales causas de la destrucción de la libertad en las repúblicas antiguas, de las tormentas que las han sacudido, de la debilidad que las ha entregado a tiranos extranjeros ${ }^{17}$.

Quedan así contrapuestas la igualdad formal y la real con una anticipación digna de ser subrayada. $Y$ la igualdad real es reivindicada por el ilustrado masón para todos los humanos, sin distinción de sexos (CONDORCET es uno de los primeros defensores de los derechos de la mujer), ni de razas (es asimismo uno de los primeros abolicionistas de la esclavitud), ni de pueblos (defiende la solidaridad mundial, fustigando la falacia de predicar la igualdad y la libertad en el país propio y desentenderse del resto del género humano) ${ }^{18}$.

Esta igualdad real es uno de los fines que justifican la vida del hombre en sociedad: "Habiéndose reunido los hombres en sociedad para el mantenimiento de sus derechos naturales, y siendo estos derechos los mismos para todos, la sociedad debe asegurar a cada uno el disfrute de los mismos derechos"19.

El mantenimiento de los derechos es, por tanto, una tarea positiva de la sociedad (o, lo que es igual, de sus órganos rectores, de los

17 Condorcet: Bosquejo de un cuadro histórico de los progresos del espíritu humano, cito por la ed. cast. preparada por mi mismo, Madrid, 1980, p. 230.

18 Pocos años antes, Federico de Prusia dejó dicho en su maquiavélico Antimaquiavelo (cap. XVI) que el enriquecimiento propio a costa del país vecino era una manera dulce $y$ amable de hacerse uno poderoso.

19 CONDORCET: Déclaration des Droits, O. C., XII, 249-250. 
poderes públicos) y no meramente el fin al que está orientada. Pero, si bien, conforme al texto transcrito, cabrían diferencias en el disfrute de los mismos derechos, nuestro autor acierta a formular en otra obra suya el principio de igualdad en su sentido fuerte: "La igualdad, que es el disfrute igual de los mismos derechos..." 20 . Si el disfrute de los mismos derechos puede ser calificado como igualdad formal (a nadie se le cercena legalmente el acceso a ningún derechol, el disfrute igual de los mismos derechos es lo que hoy denominamos igualdad real y efectiva.

Esta igualdad es la que, como antes vimos, se erige en tarea política positiva de los poderes públicos, según la concepción de nuestro autor. Por ejemplo, la desigualdad entre los propietarios de bienes hereditarios y los trabajadores exige subvenir al infortunio de éstos $-y$ de sus mujeres e hijos - mediante socorros y previsiones que los remedien y aseguren, lo cual también puede ser procurado por asociaciones particulares ${ }^{21}$. La acción pública en estos cometidos es, pues, perfectamente compatible con las iniciativas de la sociedad civil.

En esta tarea política los poderes públicos deben corregir las desigualdades institucionales, derogar los abusos y los privilegios, sin respeto a supuestos derechos mal adquiridos, sin discriminaciones de ningún tipo, sin detenerse ante nada. En síntesis y con las propias palabras de CONDORCET: "Su poder (el de los órganos rectores de la sociedad) no tiene límites en el establecimiento de la igualdad"22.

Reparemos en que esto lo dice un liberal abstencionista y percibiremos que el tratamiento de la igualdad en su sentido hondo debe excepcionar la doctrina general de la reducción del poder público a mínimos, reducción que CONDORCET defiende para todo lo demás. EI liberalismo de la siguiente centuria y el hoy emergente por doquier como "pensamiento único" caminó y camina por otros derroteros.

Para el pensamiento liberal que nos ha llegado ${ }^{23}$, una vez abolidos los privilegios, los ciudadanos son iguales. La ley, por tanto, debe ser general, lo que vale tanto como decir igual para todos. Pero ¿es verdad que los hombres son iguales y que interaccionan en condiciones de igualdad? Se atribuye a Abraham Lincoln, nada sospechoso, por

20 Id.: Essay sur les Assemblées Provinciaux, ob. cit., p. 291; cfr. Lettres d'un bourgeois gentilhomme..., ob. cit., p. 308.

21 Id.: Bosquejo..., ob. y ed. cit., pp. 231-232.

22 Id.: Déclaration des Droits, ob. cit., p. 291.

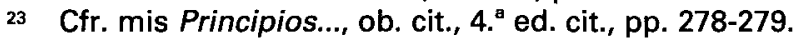


cierto, de inclinaciones socialistas, la frase "todos los hombres nacen iguales, pero ésa es la última vez que lo son".

Es a dicho liberalismo al que se opone el pensamiento socialista, para el cual los sujetos no parten en condiciones de igualdad, sino que la igualdad es algo por alcanzar. Dado ese punto de partida desigual, la generalidad de la ley no es instrumento de igualdad, sino de perpetuación de la desigualdad. El legislador debe saber distinguir entre las diferentes condiciones reales en que se encuentran los ciudadanos, individual o grupalmente considerados, para darles a cada uno lo suyo.

Para el pensamiento liberal extendido y asentado en Europa y en América durante más de un siglo, la igualdad es una condición jurídica ya existente y operante; para el socialista, una conquista política. El primero exige la igualdad como un elemento estructural de la norma, que debe hacer abstracción de las diferentes circunstancias de cada sujeto jurídico. El segundo exige introducir un trato diferencial como elemento estructural de la norma para alcanzar la igualdad.

Estas dos concepciones han llegado hasta nosotros muy matizadas y reciprocamente influidas. Los ordenamientos jurídicos, partiendo de la primera de ellas, han ido dando entrada paulatinamente a la segunda en forma de derechos sociales y económicos y de principios o programas de política social y económica. Pero cada intérprete pone el acento preferentemente en aquélla o en ésta según la ideología profesada.

Así sucedió inicialmente en los estudios sobre la Constitución española. El problema se centró en una comparación entre los artículos 9.2 (igualdad efectiva) y 14 (igualdad ante la ley) y en un pronunciamiento sobre su respectiva importancia en un Estado social y democrático de Derecho. Desde una posición se destacó la especial protección constitucional de que goza el artículo 14, la igualdad jurídica, frente a los principios de política social y económica e incluso frente al artículo 9.2; ese último precepto, no sería sino una declaración de principios de índole general, carente incluso de estructura normativa. Desde la otra se intentó poner de relieve la importancia de que el artículo 9.2 se ubique en el titulo preliminar, donde se encuentran los principios políticos del régimen que la Constitución instaura, a cuya luz debe interpretarse el resto del articulado constitucional y del Ordenamiento jurídico; la igualdad jurídica quedaba reducida a un precepto clásico, de escaso alcance, que no podía ser rémora a la declaración de igualdad 
real y efectiva, la cual era considerada una verdadera cláusula de transformación de la sociedad.

Me parece, no obstante, que un análisis de la Constitución no puede prescindir de ninguno de sus preceptos, ni tampoco enfrentarlos, sino interpretarlos integradoramente. Cada uno de los dos preceptos que estamos considerando informa el Ordenamiento jurídico y la actuación de los poderes públicos como lo que es: un principio jurídico y uno político respectivamente; pero uno y otro formulados en normas jurídicas vigentes y del mismo rango. La interpretación debe buscar la modulación recíproca de ambos principios. La igualdad jurídica no puede prescindir de la orientación política del régimen y tendrá mucho que ver con la de las sucesivas mayorias parlamentarias. Viceversa: la igualdad como tarea política no puede hacerse de espaldas al Derecho, sino que debe encontrar en éste su cauce y su límite.

El legislador no puede adoptar una concepción formalista de la igualdad como equivalente a la generalidad de la ley, sino que está obligado a atender los elementos diferenciadores de categorías, grupos y subgrupos de ciudadanos, hasta llegar excepcionalmente a la ley singular si ello fuere preciso. Pero tampoco puede inspirarse sólo en el principio de igualdad como tarea política y como resultado de la misma hasta hacer de esas leyes singulares la regla y de la generalidad la excepción; se arruinaría el tráfico jurídico y, a la postre, la consecución de ese fin político perseguido. No podemos desconocer, a la altura de los tiempos en que estamos, que hay ya materias o facetas de la vida humana en las que, también excepcionalmente, una norma absolutamente general, uniforme, es exponente de mayor igualdad que la hipótesis contraria; por ejemplo, la universalidad del sufragio, la abolición de la pena de muerte, la prohibición de la tortura sin posible excepción, etc. La generalidad de la ley es, en estos ámbitos, más progresista e igualitaria que las diferenciaciones de individuos y grupos.

En un Estado social y democrático de Derecho, el legislador está orientado a la igualdad real y efectiva como fin político. Pero atemperará el ritmo a las exigencias de la seguridad y del tráfico jurídicos, $y$, como dice el Tribunal Constitucional, a las posiciones favorables legitimamente adquiridas por ciertos ciudadanos, a los derechos constitucionalmente consagrados, a otros bienes y fines tutelados también constitucionalmente; en fin, a todos y cada uno de los principios informadores del Estado de Derecho; y, entre ellos, a la igualdad juridica. Dicho de otra manera y a guisa de conclusión: la igualdad como princi- 
pio político, la igualdad real y efectiva, es estímulo y ariete de la función legislativa24; la igualdad jurídica, su límite.

\section{LA IGUALDAD REAL Y EFECTIVA COMO INGREDIENTE DE LA IGUALDAD ANTE LA LEY}

El Tribunal Constitucional español, aunque de modo discontinuo, ha asentado una importante jurisprudencia acerca del principio de igualdad, en la que, según creo, se corroboran los anteriores asertos.

Diferencia, desde luego, el Tribunal entre igualdad jurídica e igualdad material, $\mathrm{o}$, en los términos antes utilizados por nosotros, entre el principio jurídico y el principio político de igualdad. Opina el Tribunal que el artículo 14 de la Constitución, al establecer el principio general de igualdad ante la ley, limita el poder legislativo y el de los demás operadores, fundamentalmente la Administración y los tribunales de justicia. Esta igualdad jurídica significa que a supuestos de hecho iguales se aplicarán consecuencias jurídicas iguales y que para apreciar diferencias entre los supuestos de hecho a fin de aplicarles un trato jurídico distinto tiene que haber una justificación suficiente, fundada y razonable, de acuerdo con criterios y juicios de valor generalmente aceptados ${ }^{25}$.

Este canon de la relevancia jurídica del elemento diferenciador trata de apreciar si tal diferencia debe o puede tener como consecuencia un trato jurídico diferenciado precisamente desde el punto de vista o razón de ser de la norma en cuestión. Por ejemplo, la diferencia entre funcionario y trabajador por cuenta ajena es relevante a ciertos efectos, como los del derecho de huelga, pero no a otros, como la libertad de expresión o el derecho de sufragio ${ }^{26}$; la diferencia entre hombre y mujer no es relevante en materia de derechos políticos, pero sí, por ejemplo, respecto del disfrute de permiso laboral por parto; la diferencia entre militar y civil es relevante para agravar las penas en la legislación militar, pero no en orden a la responsabilidad civil contractual27. Los ejemplos podrían multiplicarse.

24 Y también, mudando lo mudable, de los demás poderes públicos.

STC 49/1982, de 14 de julio.

SSTC de 2-VII-1981; 49/1982, citada; 59/1982, de 28 de julio; 65/1983, de 21 de julio; 83/1984, de 24 de julio; 90/1984, de 5 de octubre; 103/1984, de 22 de noviembre; 104/1984, de 23 de noviembre, etc.

27 SSTC 151/1985, de 5 de noviembre, y 107/1986, de 24 de julio. 
En sintesis, el principio jurídico de igualdad equivale a la prohibición de discriminaciones; y hay discriminación cuando se da arbitrariamente un trato jurídico diferenciado a situaciones iguales y viceversa. La discriminación comporta arbitrariedad (cuya interdicción establece el artículo 9.3 de la Constitución de modo expreso) y se identifica con la desigualdad carente de justificación objetiva y razonable y con la no estimación, igualmente injustificada, de diferencias que deben ser jurídicamente relevantes ${ }^{28}$.

La clave en el estudio de la igualdad la proporciona la propia locución utilizada por el artículo 14: "sin que pueda prevalecer discriminación alguna"; o, dicho más sintéticamente, la prohibición de discriminación. Pues, a la postre, el margen de tolerancia de la desigualdad quiebra ante la diferencia desproporcionada, no razonable, injustificable, y en esa sinrazón y desproporción consiste la discriminación.

La actuación de los poderes públicos frente a las discriminaciones depende de si éstas son producidas con ocasión de la aplicación de normas con rango de ley o se contienen en estas mismas normas; dicho de otra manera: si la discriminación es atribuible al legislador o a los demás poderes públicos. Si lo segundo, la corrección se alcanzará en vía judicial o, en último extremo, mediante el amparo constitucional. Si lo primero, la vía procedente es la declaración de inconstitucionalidad de la norma legal por parte del Tribunal Constitucional.

Hasta aquí no hemos salido del ámbito de la igualdad jurídica, que, conforme a las doctrinas más o menos explícitas de los tribunales Constitucional y Europeo de Derechos Humanos, incluye la igualdad ante la ley y la igualdad en la ley. Todavía no hemos salido del artículo 14 de la Constitución debidamente -esto es: ampliamente- interpretado. Es harto difícil que el órgano judicial deba resolver un caso concreto aplicando el artículo 9.2 de la Constitución, es decir, intentando promover las condiciones de una igualdad real y efectiva y remover los obstáculos que ésta encuentre, puesto que dicho precepto no incorpora derecho subjetivo alguno tutelable por aquél. Incluso cuando pronuncia la nulidad de un reglamento que juzgue discriminatorio, no sale de la órbita del artículo 14.

En cambio, el Legislativo y el Ejecutivo sí pueden actuar movidos por el artículo 9.2, adoptando una actividad promotora y remotora del mismo Ordenamiento, bien de normas legales, bien de normas infrale-

28 SSTC 34/1981, de 10 de noviembre; 7/1982, de 26 de febrero; 67/1982, de 15 de noviembre; 75/1983, de 3 de agosto; 83/1984, citada, etc. 
gales, vía regulación innovadora, vía reforma o vía derogación de las mismas.

No es ociosa, por tanto, la presencia en el texto constitucional de un precepto como el artículo 9.2. Antes dijimos que los dos principios se modulan recíprocamente. $Y$ de modulación habla expresamente el Tribunal Constitucional: "La incidencia del mandato contenido en el artículo 9.2 sobre el que... encierra el artículo 14 supone una modulación de este último, en el sentido, por ejemplo, de que no podrá reputarse de (sic) discriminatoria... la acción... en beneficio de determinados colectivos históricamente preteridos y marginados, a fin de que... vean suavizada o compensada su situación de desigualdad sustancial»29. Como podemos comprobar, el artículo 9.2 proporciona una cobertura explícita para las mencionadas actuaciones de los poderes públicos, una conexión social del Ordenamiento, en expresión de J. JIMÉNEZ CAMPO ${ }^{30}$, un punto de conexión teleológico, como prefiere denominarlo J. A. MONTILLA ${ }^{31}$, que habilita, facilita o impone (el Tribunal Constitucional utiliza una cierta variedad semántica al respecto) una interpretación del artículo 14 en línea con la declaración que el artículo 1.1 hace del Estado como social y democrático de Derecho.

Ahora bien, ¿equivale no ociosidad a necesidad?; ¿era necesaria esa cobertura constitucional explícita? La respuesta es claramente negativa. ¿Cómo, en otro caso, podría solucionarse el problema en otros sistemas constitucionales cuya norma suprema carece de un precepto similar?

La clave se halla en el ámbito o extensión que se reconozca al concepto de discriminación y, por ende, a la lucha para erradicarla. Si circunscribimos el concepto de discriminación a la contenida en la norma jurídica o acaecida con ocasión de su aplicación, resulta indispensable un apoyo jurídico expreso para esa actividad promotora y remotora antes descrita. Pero si, adoptado este concepto en una acepción

29 STC 216/1993, de 14 de noviembre; cfr. SSTC 114/1983, de 6 de diciembre; 98/1985, de 29 de julio; 128/1987, de 16 de julio; 166/1988, de 26 de septiembre; 19/1989, de 31 de enero; 145/1991, de 1 de julio; 109/1993, de 25 de marzo, etc.

30 JIMÉNEZ CAMPO, J.: "La igualdad jurídica como límite frente al legislador", REDC, n. ${ }^{\circ} 9$, Madrid, 1983, p. 94.

31 Montilla Martos, J. A.: «El mandato constitucional de promoción de la igualdad real y efectiva en la jurisprudencia constitucional. Su integración con el principio de igualdad", en VV.AA.: Estudios de Derecho Público. Homenaje a Juan José Ruiz-Rico, Madrid, 1997, vol. I, p. 454. 
más amplia, incorpora las situaciones, más fácticas que jurídicas, existentes en sociedades, como la nuestra, asentadas secularmente en una cultura de desigualdades injustificables, entonces cabe calificar como discriminatorio un estatuto jurídico determinado - el de la mujer, verbigracia, o el de una minoría étnica - aunque las normas que lo integren no sean directamente discriminatorias en su propio enunciado $y$ estructura. Ese estatuto jurídico o algunas de sus normas integrantes resultan discriminatorios no por lo que dicen, sino por lo que callan u omiten; esto es, por limitarse a regular asépticamente unas relaciones sociales sin cuestionarse el trasfondo de las mismas, por no remover obstáculos formales y no promover condiciones nuevas para alcanzar una igualdad real y efectiva, o por no intentarlo al menos; en fin, por no derogar, reformar a fondo o regular innovadoramente esas relaciones sociales introduciendo en el nuevo estatuto jurídico tratamientos diferenciados hasta entonces inexistentes con vistas a equilibrar en el futuro lo que hoy está desequilibrado ${ }^{32}$, buscando la igualdad real y efectiva como tarea política positiva.

Asumido lo anterior en los términos dichos, el principio político de igualdad, la igualdad real y efectiva como conquista, como punto de llegada, no sólo no esta enfrentado, ni real ni dialécticamente, al principio jurídico de igualdad, a la igualdad ante la ley y en la ley, sino que es su proyección más plausible en un Estado social y democrático de Derecho. En éste, la igualdad no es ni puede ser únicamente formal, sino también real, sin mengua de su juridicidad; la igualdad no puede medirse meramente en términos de presente, sino también de futuro. En un Estado social y democrático de Derecho, para que haya igualdad ante la ley $y$ en la ley, es preciso que ésta, la ley, no omita lo necesario para evitar discriminaciones; si no las evita, no sólo hay discriminación de hecho, sino que la ley puede resultar discriminatoria por no procurar su remedio.

La respuesta a las preguntas que nos hacíamos un poco más arriba se nos aparece ahora mas nítida: interpretada la igualdad jurídica acorde con las exigencias de un Estado social y democrático de Derecho, se proyecta también sobre esas relaciones sociales que siguen siendo discriminatorias a pesar de la asepsia de la norma y de su aplicación por los operadores jurídicos. Es decir, la igualdad jurídi-

32 Como señaló tempranamente J. Jiménez CAMPo (ob. cit., p. 96), no es preciso que la discriminación sea actual, sino que puede ser potencial; basta, creo, con que sea previsible conforme a la evolución conocida de las demandas sociales. 
ca tiene una inesquivable vocación de efectividad; la igualdad ante $y$ en la ley busca activamente que también la haya en la realidad que regula. $Y$, por consiguiente, seguimos dentro del ámbito del artículo 14 sin necesidad de invocar la ayuda del 9.2. Sin necesidad, digo, pero acaso con la conveniencia de hacerlo dada la explicitud de su enunciado. El artículo 9.2, en conclusión, no era necesario, en el sentido de absoluta y esencialmente imprescindible para el cometido comentado, pero tampoco ocioso, dado que facilita la cobertura jurídica de la acción afirmativa de los poderes públicos en pro de la igualdad real y efectiva, haciendo prescindibles interpretaciones más prolijas.

No sé si el único, pero sí el primero que apuntó en esta dirección fue I. DE OTTO: «El artículo 9.2 del texto constitucional puede, en consecuencia, reinterpretarse de un modo más adecuado como formulación de un doble mandato, de lo que se ha llamado una "política de derechos fundamentales" - esto es, de una política de creación de las condiciones efectivas y reales de la libertad y de la democracia- y de una "política de bienestar social" que se concreta sobre todo en los principios rectores de la política social y económica que se recogen en el Capítulo III del Título I de la Constitución ${ }^{33 .}$

Pues bien, esto y no otra cosa es lo que ha hecho el Tribunal Constitucional ${ }^{34}$, bien escoltado por el Tribunal Europeo de Derechos Humanos. Ni uno ni otro hacen declaraciones expresas en tal sentido, pero no puede entenderse su doctrina si lo antes afirmado no es asumido como sustrato de su intelección de la igualdad.

El criterio más utilizado por ambos tribunales a este respecto es el de la proporcionalidad entre la finalidad constitucionalmente lícita de propiciar una igualdad real y efectiva y los medios empleados para ello. El Tribunal Europeo, desde hace más de treinta años, viene sosteniendo que ciertas desigualdades de derecho tienden a corregir desigualdades de hecho $y$, por ende, a conseguir una igualdad real. Para valorar tales actuaciones debe ponerse en relación esa finalidad (que ha de ser legítima) y los efectos de la medida examinada con los medios empleados, todo ello a la luz de los principios que generalmente prevalecen en las sociedades democráticas ${ }^{35}$.

33 Oтто, I. de: ob. cit., p. 454.

34 Cfr., entre otras muchas, SSTC 34/1981, citada; 3/1983, de 25 de enero; 23/1984, de 20 de febrero, y 93/1984, de 16 de octubre.

35 SSTEDH de 23-VII-1968, caso lingüístico belga, y de 13-1II-1979, caso Marcks, entre otras. 
Como vemos, el Tribunal Europeo aporta con ello otra idea para una siempre relativa precisión de este criterio: aquellos juicios de valor generalmente aceptados no son cualesquiera juicios socialmente extendidos, sino los que prevalecen en las sociedades democráticas en cuanto democráticas. De otro lado, el Tribunal Constitucional español, adopta también el criterio de que se deben tener igualmente en cuenta los efectos de la medida adoptada, puesto que en función de la igualdad real y efectiva no se puede dar lugar a resultados contrarios a los derechos y libertades constitucionales ni pueden producirse normas contrarias a otros preceptos o principios de la Constitución, como tampoco se puede con tal motivo vulnerar el principio jurídico de igualdad, el cual rechaza las diferencias discriminatorias ${ }^{36}$. Dicho con pocas palabras: el principio político de igualdad orienta al legislador; el principio de igualdad jurídica lo limita.

Los poderes públicos, dice el Tribunal Consitucional, deben promover los valores superiores del Ordenamiento, lo que requiere de ellos actuaciones positivas a fin de remover obstáculos y promover condiciones y cauces institucionales para esa efectividad de la libertad $y$ de la igualdad y para la solución de los conflictos sociales ${ }^{37}$. Por tanto, el legislador puede introducir conscientemente ciertas diferencias de tratamiento jurídico con vistas a la igualdad real y efectiva ${ }^{38}$.

En este ámbito se inscribe, por ejemplo, la acción positiva o afirmativa en beneficio de la igualdad real de la mujer ${ }^{39}$. (No obstante, debe poner el legislador cuidado para que la protección de la mujer no se le vuelva en contra perpetuando su situación discriminatoria; de ser asi, la medida sería doblemente vulneradora de la igualdad, pues discriminaria al varón en el presente prolongando la desigualdad de la mujer en el futuro ${ }^{40}$. Lo mismo debe decirse de la realizada en pro de una igualdad más efectiva del minusválido ${ }^{41}$. El Derecho laboral también se basa en este principio político de la igualdad, puesto que intro-

36 SSTC $34 / 1981$ y $75 / 1983$, citadas.

37 SSTC 6 y 11/1981, de 16 de marzo y 8 de abril.

38 SSTC 27 y 34/1981, de 20 de julio y 10 de noviembre; 3/1983, citada; 24 y 93/1984, de 20 de febrero $\vee 16$ de octubre; 98/1985, de 29 de julio, y 19/1988, de 16 de febrero, etc.

39 Por todas, STC 216/1991, de 14 de noviembre.

40 STC 128/1987, de 16 de julio; 229/1992, de 14 de diciembre; 3/1993, de 14 de enero; 109/1993, de 25 de febrero, y 317/1994, de 28 de noviembre, entre otras; cfr. STC $315 / 1994$, de igual fecha.

41 Cfr. STC 269/1994, de 3 de octubre, y STS de 20-VI-1989 (RA 4.680). 
duce desigualdades jurídicas que corrigen y compensan las desigualdades sociales preexistentes ${ }^{42}$.

Por último, el Tribunal Constitucional valida igualmente las leyes singulares en razón de la igualdad. La igualdad ante la ley exige, en principio, leyes generales, pero no prohíbe al legislador contemplar la necesidad o la conveniencia de regular situaciones distintas con un tratamiento diverso. La ley singular, por tanto, debe responder a una situación de igual índole y ser una medida razonable y proporcionada al supuesto de hecho sobre el que se proyecta ${ }^{43}$.

Lo interesante para la hipótesis de trabajo de estas páginas $y$ más en concreto del presente epígrafe, es que el Tribunal Constitucional, en ocasiones, prefiere hacer una interpretación material del artículo 14, hallando en él una noción sustancial de la igualdad, en la cual se incluye buena parte del significado del artículo 9.2, si no todo él, citándolo o sin citarlo. Con lo que la remoción de obstáculos y la promoción de condiciones en pro de la igualdad real y efectiva pueden apoyarse en el artículo $14^{44}$.

Esta oscilación del más alto intérprete de la Constitución merece el reproche de A. GARRORENA ${ }^{45}$ y J. A. MONTILLA ${ }^{46}$, puesto que -dice el segundo de estos autores - el mandato constitucional de promoción de la igualdad real y efectiva, aun con limitaciones, se contiene en el artículo 9.2. Pero así sucede con alguna frecuencia y, a mi juicio, no incorrectamente. Nada digamos cuando el Tribunal da a entender que es imposible fundamentar ciertas medidas jurídicas diferenciadoras en el artículo 9.2 porque el actor no pretende la remoción de ciertos obstáculos, sino medidas protectores o de mejor trato jurídico ${ }^{47}$.

En fin, como aduce el propio J. A. MONTILLA ${ }^{48}$, el artículo 9.2 no tiene eficacia autónoma como parámetro de constitucionalidad. Por eso, su proyección más plausible es la de matizar y modular la interpretación del artículo 14 (interpretación que debe hacerse uen el marco que le prestan los artículos 1 [1] y 9 [2] de la Constitución"), introduciendo en él su carga semántica. Así lo hacen, entre otras, las SSTC

42 STS de 19-II-1985 (RA 666).

43 STC 166/1986, de 19 de diciembre.

44 Cfr. SSTC 19/1989 y 145/1991, citadas.

45 Garrorena, A.: El Estado español como Estado social y democrático de Derecho, 2. ${ }^{\circ}$ ed., Madrid, 1984, pp. 64-65.

46 Montilla Martos, J. A.: ob. cit., p. 454.

47 Cfr. STC 19/1989, citada.

48 Montilla Martos, J. A.: ob. cit., pp. 456-457. 
216/1991, de 14 de diciembre, y 177/1993, de 31 de mayo, a la segunda de las cuales pertenece la frase entrecomillada.

A la vista de esta línea jurisprudencial concluía yo en 1992 de la siguiente forma: "...si la igualdad en la ley (no sólo ante la ley) del artículo 14 habilita a los poderes públicos a introducir en la norma tratamientos diferenciados en pro de la igualdad real, entonces el artículo 9. 2 devendría superfluo, a despecho de la mucha tinta vertida en su exégisis. Pero el Tribunal, en otras ocasiones, vuelve a la contraposición de ambos preceptos y aspectos de la igualdad" 49 .

En el presente año, 1998, he insistido por extenso en la misma línea: "Pero acaso lo más interesante de toda esta línea jurisprudencial es que nuestro Tribunal Constitucional, como hizo antes el Tribunal Europeo de Derechos Humanos, ha entendido desde su inicio que el principio juridico de igualdad da cobertura al principio politico (...) La trascendencia de esta tesis es extraordinaria, pues el principio de igualdad juridica de este precepto está protegido por el recurso de amparo y, por consiguiente, cualquier ciudadano que se vea discriminado... puede instar la tutela del juez ordinario $\gamma$, en su caso, el amparo de la jurisdicción constitucional, corrigiéndose así la imposibilidad de invocación del artículo 9.2, que no es susceptible de amparo. Se gana asi mucho en la protección de los ciudadanos y en la lucha contra la discriminación, aunque sea al precio de relegar y vaciar en parte el contenido del artículo 9.2. A veces, como ha señalado J. A. MONTILLA, el Tribunal integra los dos preceptos en su argumentación, interpretando el artículo 14 a la luz del aporte finalista que le proporciona su conexión con el 9.2; pero, a mi juicio, las más de las veces la apelación a este precepto es oblicua, indirecta (por ejemplo, dice interpretar el artículo 14 de acuerdo con las exigencias del Estado social, lo que obviamente es diferente) y, con frecuencia, a mayor abundamiento, esto es, como refuerzo de una argumentación basada en el artículo 14 y consistente por si sola"50.

No obstante, creo prudente añadir ahora, en línea con lo sostenido en estas reflexiones, que el artículo 9.2 sigue conservando la funcionalidad de facilitar una interpretación del artículo 14 como atinente también a la igualdad real y efectiva por cuanto la integración de ambos preceptos proporciona una cobertura constitucional explícita para ello.

49 Torres del Moral, A.: Principios..., ob. cit., 3. ${ }^{\text {a }}$ ed., Madrid, 1992, vol. I, p. 378.

Ibidem, 4. ${ }^{B}$ ed., Madrid, 1998, p. 283. 